\title{
An Intrinsic Study on Routing Protocols in Mobile Ad-Hoc Network
}

\author{
A. Sangeetha M.C.A., M. Phil. \\ Assistant Professor, Department of Computer Science \\ Bharathiar University Arts and Science College \\ (Modakkurichi), Sivagiri.-638 109. \\ Cell: 9003022630 \\ Email: sangeearun2008@gmail.com
}

\author{
Dr. T. Rajendran M. Sc., M.Phil., \\ M. E, Ph. D, Miste \\ Assistant Professor, \\ Department of Computer Science \\ Arignar Anna Government Arts College for Men \\ Namakkal- 637002. Cell: 9894676746 \\ Email: rajendran_tm@yahoo.com
}

\begin{abstract}
Mobile Ad-Hoc Networks (MANET) are becoming an emanating technology among mobile devices. It is a structure less network of independent collection of wireless mobile nodes [Smart phones, Laptops, iPads, PDAs, Sensors etc.] connected by wireless links. Routing in Ad-hoc networks is challenging due to mobility of nodes and dynamically changing topology. The primary objective of the routing protocols is to establish an optimal and efficient route between the communicating nodes. Due to different network environments like varying number of nodes, speed, network load, it is difficult to figure out which routing protocol may perform well. This study investigates the performance and behavior of MANET routing protocols such as DSDV, AODV, NCPR and ZRP with a special focus on their comparison, functionality and issues. In this review, we analyzed about the protocols based on various quantitative parameters such as average throughput, packet delivery ratio, routing overhead and average end to end delay.
\end{abstract}

Index Terms-MANET, Routing Protocols, DSDV, AODV, NCPR, ZRP, Performance Metrics.

\section{InTRODUCTION}

Communication is essential for transferring information between peoples, computers at anywhere, any time. In general, wireless communication networks are implemented and managed using radio communication system. There are two types of wireless network [1]:

\section{Infrastructured Wireless Networks}

The communication between nodes are established and maintained through central controller. Any node can be joined to the network through wireless access point. Examples include the cellular network and wireless local network. Structure less or Wireless Ad-Hoc Networks

Structure less networks are not depends up on the base station to manage the routing of packets to other nodes. In addition, each individual node establishes routing path to the destination by itself and forward packets in a multi-hop way through several gateways. This type of network used in emergency situations, disaster relief, military fields, WSN, video conferencing, etc.

Mobile Ad-Hoc Network (MANET)[2] is a infrastructure less network formed with wireless mobile hosts such as computers, cell phones, sensor nodes, etc.

Each node communicates with other through wireless links and the hosts can freely connect and disconnect from the network. Simultaneously, each mobile node acts as a router. Routers can easily and randomly move hence network topology can dynamically change. The transmission range of each node in MANET is limited, so packets are transmitted based on multi-hop, peer to peer manner from a source to a destination node or nodes. These networks have many constraints like available bandwidth, limited power, and limited physical security.

\section{Routing in MANET}

Routing is a process of finding a shortest, stable, and secure route from a source node to ultimate destination node through intermediate nodes in the network. MANET routing protocols consist of routing algorithm and software to establish optimal communication and data transfer path between nodes. Routing algorithms should act correctly in unusual or unforeseen circumstances, such as link breakage, hardware failures, high load conditions, and incorrect implementations to maintain the consistency of the network. The routing protocols must have the following key features [3]:

Dynamic nature : The routing protocol should not rely on central controlling point and. 
It should support for topology change because the nodes may detach and attach to the network at any time.

On Demand routing: It should determine the route only when it is required by the source node for transmitting packets.

Loop freedom: Transmission of same route request message by multiple path leads to wastage of bandwidth and power. So routes should be free from loop.

Multiple routes: The protocol must determine more than one route to the destination node. If there is a problem in route, another route can be used without initiating route request.

Energy conservation: The routing protocols must reduce power consumption and support sleep mode because mobile nodes operate on battery power and nodes are having limited battery power.

Quality of service: To reduce overhead, some kind of Qos is needed in routing protocols.

\section{Classification Of Routing Protocols}

Routing protocols in MANET can be categorized [4] into three types depends on the routing strategy and network structure.

\section{Proactive routing protocol or Table-driven}

The proactive routing protocols maintain up-to-date routing information about all the nodes in every nodes routing table. Nodes transmit the packets to the other nodes in the network using the table. Whenever there is a change in the network topology, these protocols use two kinds of updates such as periodic and triggered update to update the routing table.

Example: Destination Sequenced Distance vector (DSDV), Cluster head Gateway Switching Protocol (CGSP), Global State Routing (GSR), Fisheye State Routing (FSR), Hierarchical State Routing (HSR) and Source Tree Adaptive Routing (STAR).

\section{Reactive routing protocol or On-demand}

In Reactive routing protocols, route is established only when it is required. This protocol periodically updates their routing table with latest routing information. This protocol contains two processes: route discovery and route maintenance. When a source node wants to communicate with destination node, it starts a route discovery process by broadcasting route request packet to its neighbors. The route maintenance process is used when source node detects any change in topology or route becomes unavailable or destination node is unreachable.

Example: Ad-hoc On Demand Distance Vector (AODV), Dynamic Source Routing (DSR), Temporary Ordered Routing Algorithm (TORA), Cluster Based Routing Protocols (CBRP), Neighbor coverage-based probabilistic rebroadcast protocol (NCPR).

\section{Hybrid Routing Protocol}

Hybrid protocol combines the feature of both proactive and reactive routing protocol. This protocol divides the nodes into number of zones and clusters. When number of nodes increased, the performance of the hybrid protocol is highly improved.

Example: Zone Routing Protocol (ZRP), Hazy Sighted Link State (HSLS) protocol, Secure Routing Protocol (SRP), Hybrid Ad hoc Routing Protocol (HARP).

The rest of the paper presents a brief survey on few of the MANET routing protocols. Section II discusses various routing protocols under consideration, Section III gives the literature review, Section IV presents simulation and comparative analysis using network simulator, Section V discusses open technical issues and finally, Section VI presents conclusion of this work.

\section{OVERVIEW OF ROUTING PROTOCOLS}

DSDV (Destination Sequenced Distance Vector) DSDV [5] is a proactive routing protocol and it is based on the idea of Bellman-Ford Routing algorithm to calculate path. Each node maintains a routing table which contains the next hop, cost metrics to reach the destination. The routing table is forwarded to next hop to select the shortest path. When route changes are propagated, looping in routing within the network occurs. To eliminate routing loops, latest destination sequence number is used. In DSDV, if the link is not present, the sequence number will be odd else even number is used. DSDV uses distance vector shortest path routing algorithm to find a single path from source node to a destination node.

\section{AODV (Ad-Hoc On Demand Distance Vector)}

AODV is a dynamic, unicast routing protocol. This protocol is designed to reduce the traffic of control and data packets there by increasing the performance of the network. It[6] is the combination of DSDV and DSR routing protocols. To discover and maintain the routes, AODV uses the demand based routing method of DSR protocol and sequence numbers, periodic beacons from DSDV. It uses hop-by-hop routing. When a node want to communicate with other node, it transmits route request (RREQ) packet to the neighbor until intended destination is reached. The destination node sends the most recent route as route reply packet (RREP) to the route requests [7]. This protocol uses the destination sequence number to find freshest route and also loop free routing.

The route maintenance phase of AODV is used to handle broken links. If the source node does not receive any reply with in the timeout, it rebroadcasts query message. 


\section{NCPR (Neighbor Coverage-based Probabilistic Rebroadcast protocol)}

NCPR [8] protocol combines the approach of probabilistic method and neighbor knowledge method. Each node maintains their neighbor list. Rebroadcast probability is estimated by combining additional coverage ratio and connectivity factor. Additional coverage ratio is defined as the ratio between the number of nodes enclosed by single broadcast message to total number of neighbor nodes. Connectivity factor represents the relationship between the network connectivity and number of neighbors of the particular node. The rebroadcast traffic generated by this protocol is very less compared to other methods. This approach works better in sparse network rather than dense.

\section{ZRP (Zone Routing Protocol )}

ZRP [9] combines the advantages of both reactive and pro-active protocols. This protocol reduces the control overhead caused by proactive protocol and delay with in the zone caused by route discovery process of reactive protocol. This protocol is based on zone radius which is determined by hop count. The node may be present in more than one zone and the size of the zones are different. ZRP consists of several components like IARP, IERP and BRP which provides the full routing benefit to ZRP.

\section{LITERATURE REVIEW}

DSDV [10] has simple routing table format, simple routing operation and guarantees loop free routes. Every node has to handle route request and route reply procedure. This decreases the performance of the individual mobile node. Broadcasting route updates cause large overhead and waste resources for finding all possible routes between nodes when the network is dense. So DSDV is highly suitable for the network with low density.

In DSDV [11], new sequence number is used when there is change in the network topology. This new sequence number in turn changes the route to the destination. DSDV uses two routing table. One table is used for forwarding the packets. Second table is used for storing updated routing information. DSDV uses the incremental route update strategy to avoid additional traffic. The regular update of routing table needs additional bandwidth and battery power even in the idle state.

AODV [12] is based on distance vector algorithm to find out the unicast routes to the destination. In AODV, the routing overhead caused by control message is considerably reduced, so it requires less bandwidth. It has minimal space complexity as stale routes are deleted. It requires less storage for storing route information.
AODV [13] protocol is based on minimum delay path as route selection criteria. It issues the control signal to establish and maintain paths, which could reduce the cost of producing the path, saving a certain amount of network resources. AODV [14] performs better in dense environment except packet loss. AODV protocol reduces control message overhead and also it consumes less bandwidth. AODV uses flooding mechanism in route discovery process which causes redundant retransmission, collision and contention called as broadcast storm problem.

In NCPR[15], probabilistic broadcasting is depending on coverage area and neighbor confirmation. Coverage area scheme is used to set a rebroadcast probability and neighbor confirmation scheme make sure that all nodes should receive the broadcasting packet. NCPR dynamically calculates the rebroadcast delay to determine the forwarding order and effectively utilize the neighbor coverage knowledge. NCPR replaced the random waiting time for subsequent broadcast by rebroadcast delay based on the number of covered neighbors.

In NCPR [16], probability based and area based methods are incorporated. In probability based method, all mobile nodes set fixed predefined probability. But in MANET, nodes can change their topology dynamically. So there is no use of fixed probability. In this approach, the rebroadcast probability is dynamically set. NCPR [17] is proposed to reduce the routing overhead caused by RREQ redundant packets based on self -punning scheme. Also it reduces end to end delay and increase packet delivery ratio. But the overall broadcasting delay is increased.

In ZRP [18], interior nodes are the nodes inside the zones, uses the intra zone routing protocol (IARP) for communication. Peripheral nodes are exist on the border of the zone. Nodes outside the nodes are exterior nodes which make use of inter zone routing protocol (IERP) for data transmission. The benefit of ZRP protocol is that it decreases the communication channel as compared to the table driven protocols. It also minimizes the delay of packet delivery as compared to the on demand protocols.

The performance of ZRP [19] protocol analyzed using various performance metrics. This analysis reveals that the performance of ZRP increase in terms of throughput and decreases with normalized routing overhead and end to end delay when the network size and transmission range is increased. The demerit of ZRP is that, routing outside the zone requires more energy and memory to store large amount of routing information. 


\section{SIMULATIONAND COMPARITIVE}

ANALYSIS

The comparative study of the routing protocols AODV, DSDV, NCPR and ZRP are performed based on different qualitative and quantitative parameters. The result of quantitative comparison has been presented in the form of table.

Table 1. Qualitative comparison of routing protocols

\begin{tabular}{|c|c|c|c|c|}
\hline \begin{tabular}{|l|} 
Metrics/Prot \\
ocol
\end{tabular} & DSDV[5] & AODV[6] & NCPR[8] & ZRP[9] \\
\hline Routing Type & Proactive & Reactive & Reactive & Hybrid \\
\hline Loop Free & Yes & Yes & Yes & Yes \\
\hline \begin{tabular}{|l|} 
Routing \\
Philosophy \\
\end{tabular} & Flat & Flat & Flat & Flat \\
\hline \begin{tabular}{|l|} 
Routing \\
Scheme \\
\end{tabular} & Table driven & On demand & On demand & Both \\
\hline \begin{tabular}{|l|} 
Multicast \\
Capability \\
\end{tabular} & No & Yes & Yes & Yes \\
\hline $\begin{array}{l}\text { Routing } \\
\text { Metric }\end{array}$ & Shortest path & $\begin{array}{l}\text { Freshest } \\
\text { Shortest Path }\end{array}$ & $\begin{array}{l}\text { Shortest } \\
\text { path }\end{array}$ & $\begin{array}{l}\text { Shortest } \\
\text { path }\end{array}$ \\
\hline \begin{tabular}{|l|} 
Resource \\
Consumption \\
\end{tabular} & High & Low & $\begin{array}{l}\text { Less than } \\
\text { AODV }\end{array}$ & Medium \\
\hline \begin{tabular}{|l|} 
Security \\
\end{tabular} & No & No & No & No \\
\hline $\begin{array}{l}\text { Route } \\
\text { Discovery }\end{array}$ & Source node & Any node & Any node & $\begin{array}{l}\text { Node inside } \\
\text { t he zone }\end{array}$ \\
\hline \begin{tabular}{|l} 
Periodic \\
Update \\
\end{tabular} & Yes & No & No & Yes \\
\hline Merit & $\begin{array}{l}\text { Low latency, } \\
\text { Count to } \\
\text { infinity } \\
\text { problem is } \\
\text { removed }\end{array}$ & $\begin{array}{l}\text { Low } \\
\text { overhead, } \\
\text { Adaptable to } \\
\text { highly } \\
\text { dynamic } \\
\text { topologies, } \\
\end{array}$ & $\begin{array}{l}\text { Reduced } \\
\text { routing } \\
\text { overhead }\end{array}$ & $\begin{array}{l}\text { Suitable for } \\
\text { larger } \\
\text { network } \\
\text {,Latency is } \\
\text { low }\end{array}$ \\
\hline Demerit & $\begin{array}{l}\text { Does not } \\
\text { support } \\
\text { multipath } \\
\text { Routing,Does } \\
\text { not scale well } \\
\text { for larger and } \\
\text { dense } \\
\text { network }\end{array}$ & $\begin{array}{l}\text { Inconsistent } \\
\text { route, } \\
\text { Latency is } \\
\text { increased. }\end{array}$ & \begin{tabular}{|l|} 
Poor reach \\
ability in \\
sparse \\
network, \\
Performance \\
degradation \\
due to \\
excessive \\
hello \\
messages
\end{tabular} & \begin{tabular}{|l} 
Zone \\
consumes \\
large \\
memory, \\
Complexity \\
increases
\end{tabular} \\
\hline
\end{tabular}

\section{PERFORMANCE METRICS}

The following quantitative parameters [20] are used to evaluate the MANET routing protocols performance with variable number of nodes:

Packet Delivery Ratio (PDR): It is the ratio of the data packets delivered to the destination successfully to those sent by the source nodes. Average End to End Delay: It is the average time taken to transmit a data packet from source to destination node.
Average Throughput: It is defined as the average number of packets successfully reached to the destinations per unit time.

Normalized Routing Load (NRL): It is the ratio of average routing control packets send by sources node to number of received data packets at the destination node.

The simulation of AODV, DSDV, NCPR and ZRP has conducted using Network Simulator NS-2 [21][22]. NS-2 software provides support for simulating the routing protocols of network.

\section{Table 2. Simulation Parameters}

\begin{tabular}{|l|l|}
\hline $\begin{array}{l}\text { Simulation } \\
\text { Parameter }\end{array}$ & Values \\
\hline Simulator & NS-2 \\
\hline Environmental Size & $750 \mathrm{~m} * 750 \mathrm{~m}$ \\
\hline Number of Nodes & $20,40,60,80,100$ \\
\hline Node Pause Time & $2 \mathrm{sec}$ \\
\hline Mobility Model & Random Waypoint \\
\hline Traffic Type & CBR \\
\hline Number of connections & 30 \\
\hline Size of the packet & 512 byte \\
\hline Packet Rate & 4 Pkts/sec \\
\hline MAC Layer Protocol & IEEE 802.11 \\
\hline Protocols & $\begin{array}{l}\text { DSDV, AODV, NCPR, } \\
\text { ZRP }\end{array}$ \\
\hline
\end{tabular}

When the number of nodes in the network varies, the selected quantitative parameters of the routing protocols shows major difference in their performance

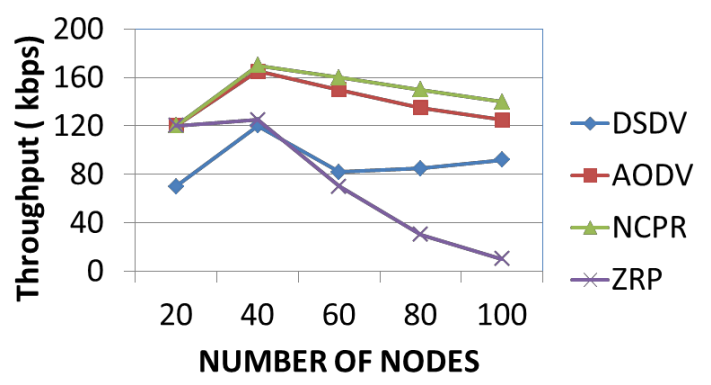

Fig.1. Throughput vs Number of nodes

Fig. 1 reveals that throughput decreases when the density of the network increases due to congestion and collision in the networks. Increase in nodes deteriorates throughput of ZRP compared to other protocols under consideration. NCPR has better performance than AODV. AODV has second better performance than DSDV. 


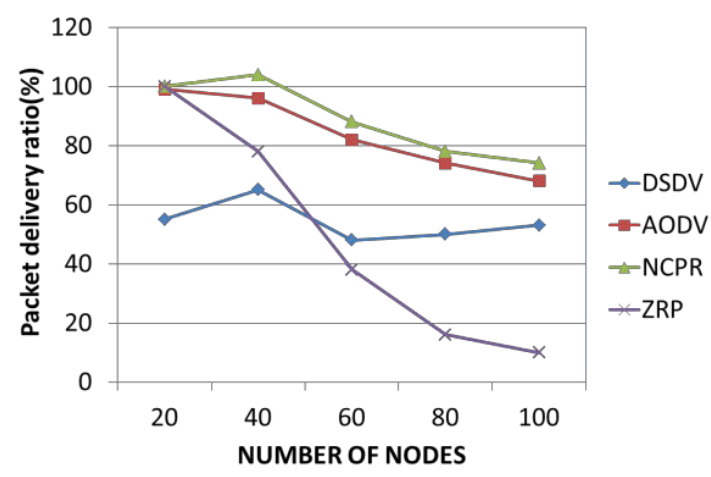

Fig.2.Packet Delivery Ratio vs Number of nodes

Fig. 2 shows that PDR rises from 20 to 40 nodes afterwards its start decreasing. AODV exhibits more or less consistent PDR with different network densities. ZRP has larger variation with increase in number of nodes. DSDV has average PDR with increasing network size. NCPR has better PDR than AODV.

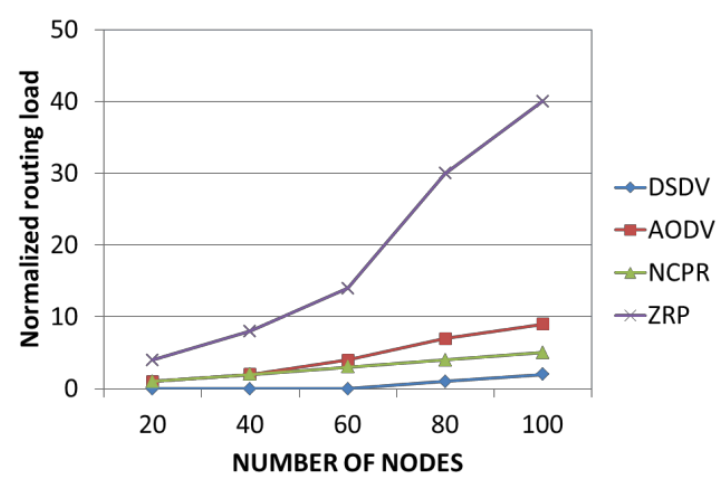

Fig.3. NRL vs Number of nodes

Fig.3 depicts that network routing load rises as number of nodes increased. DSDV maintains almost steady NRL in smaller networks. But the performance of DSDV degrades when the network size is increased. ZRP shows worst performance. AODV has increase in overhead than NCPR.

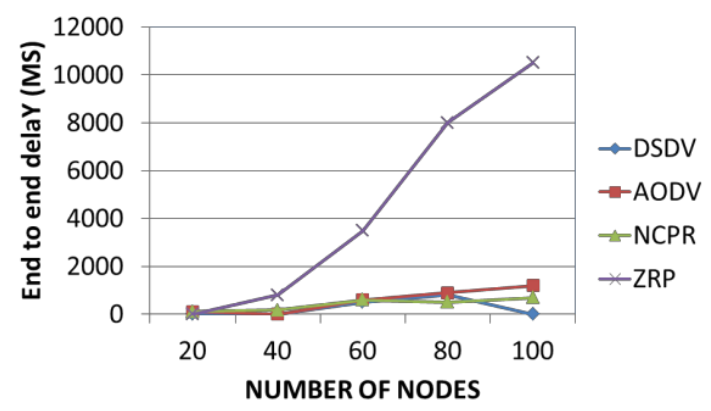

Fig.4. End to End Delay vs Number of nodes

Fig. 4 depicts that, DSDV has lesser end to end delay than NCPR and AODV. In ZRP, average end to end delay incrementally increases with increase in network density
DSDV shows nearly stable end to end delay with varying number of nodes.

From the above simulation and comparative analysis, the following table of result has been obtained.

Table 3: Comparative Analysis of Routing Protocols

\begin{tabular}{|c|c|c|c|c|}
\hline $\begin{array}{l}\text { Metrics/ } \\
\text { Protocols }\end{array}$ & DSDV & AODV & NCPR & ZRP \\
\hline Throughput & Low & Medium & High & $\begin{array}{l}\text { Very } \\
\text { Low }\end{array}$ \\
\hline $\begin{array}{l}\text { End to end } \\
\text { delay }\end{array}$ & Lowest & Medium & Small & High \\
\hline $\begin{array}{c}\text { Routing } \\
\text { Overhead }\end{array}$ & Low & High & Lowest & High \\
\hline $\begin{array}{l}\text { Packet } \\
\text { Delivery Ratio }\end{array}$ & Medium & High & $\begin{array}{l}\text { Better } \\
\text { than } \\
\text { AODV }\end{array}$ & Low \\
\hline
\end{tabular}

\section{OPEN TECHNICAL ISSUES}

The comparison of various routing protocols reveals that there are several major issues in routing protocol. In DSDV [5] protocol, incremental update strategy is used to avoid extra traffic. But bandwidth wastage and larger network overhead occurs when transferring periodic route update messages. In AODV[6][7], network overhead is increased by the transmission of several reply messages for single route request and inconsistent and stale routes are caused by intermediate nodes not having the freshest sequence numbers. While NCPR[8][15] reduces the overhead considerably, the excessive number of hello message will consume the nodes energy and introduce another overhead, which in turn negatively affects the overall system performance. Mobile networks are more vulnerable to physical security threats such as eavesdropping and jamming attacks. AODV [7][17] is vulnerable to various kinds of attacks like black hole attack. NCPR [15] also cannot provide security during communication. Nodes in MANET are typically battery powered as well as limited in storage and processing abilities. Even ZRP is suitable for dense network, energy is wasted when transmitting packets from source to destination node located in different zones. Another important issue in ZRP is the selection of zone radius on regular basis.

\section{CONCLUSION AND FUTURE WORK}

Mobile ad-hoc networking is one of the more innovative and challenging areas of wireless networking. A comprehensive analysis of MANET routing protocols and comparison of DSDV, AODV, NCPR and ZRP have been performed. There are numerous technical aspects present in various routing protocols and it is difficult to choose a single 
protocol that can adapt to the wide variety of network conditions. In future, extensive study has to be performed to provide better insight on routing overhead and security in MANET routing protocols.

\section{REFERENCES}

[1] M.Ayyash, Y.alsbou, and M.Anan, "Introduction to mobile ad-hoc and vehicular networks," in wireless Sensor and Mobile Ad-hoc networks. Springer, 2015, pp.33-46.

[2] D. Kelly, R. Raines, R. Baldwin, B.Mullins, and M. Grimaila "Towards a taxonomy of wired and wireless anonymous networks," in Proc.IEEE.ICC, Jun 2009, pp. 1-8.

[3] Bouhorma, M., Bentaouit, H. and Boudhir, A., "Performance Comparison of Ad-hoc Routing Protocols AODV and DSR ${ }^{\text {e', }}$ IEEE, International Conference on Multimedia Computing and Systems, October 2009, pp. 511-514

[4] Hui Xu, Xianren Wu Hamid R and J. J. Garcia, "Unified analysis of routing protocols in manets," IEEE transaction on communications, Vol. 58, March 2010

[5] Perkins C. E. and Bhagwat, P. ,"Highly Dynamic DestinationSequenced Distance-Vector (DSDV) for Mobile Computers", Proc. ACM Conf. Communications Architectures and Protocols, London, UK, August 1994, pp. 234-244.

[6] C. Perkins, E.Belding-Royer, and S.Das, "Ad Hoc On-Demand Distance Vector (AODV) Routing,", IETF RFC 3561, 2005.

[7] Bhatia, T., \& Verma, A. K. ,"Performance Evaluation of AODV under Blackhole Attack", International Journal of Computer Network and Information Security (IJCNIS), Vol. 5, No. 12, pp. 35-44.

[8] Xin Ming Zhang, Member, IEEE, En Bo Wang, Jing Jing Xia, an Dan Keun Sung, "A Neighbor Coverage -Based Probabilistic Rebroadcast for Reducing Routing Overhead in Mobile Ad Hoc Networks" Senior Member, IEEE. IEEE Transaction On Mobile Computing Vol. 12, No. 3, March 2013.

[9] Pearlman MR, Samar P, “ The Zone Routing Protocol (ZRP) for Ad Hoc Networks", IETF draft, July 2002, available at http://tools.ietf.org/id/draft- ietf-manetzone-zrp-04.txt.

[10] S. Mohapatraa, P. Kanungob, "Performance analysis of AODV, DSR, OLSR and DSDV Routing Protocols using NS2 Simulator," International Conference on Communication technology and System Design ELESVIER, 2011,pp.69-76.
[11] V. Arora, C.R. Krishna, "Performance Evaluation of Routing Protocols for MANETs under Different Traffic Conditions," 2nd International Conference on Computer Engineering and Technology, IEEE, Vol.6, 2010, pp.79-84

[12] Shaily Mittal and PrabhjotKaur, "Performance Comparison of AODV, DSR and ZRP Routing Protocols in MANET"S," .In 2009 International Conference on Advances in Computing, Control, and Telecommunication Technologies. IEEE, 165-168.

[13] R. Misra, C. R. Manda,"Performance comparison of AODV/DSR OnDemand Routing Protocols for Ad Hoc Networks in Constrained Situation", IEEE ICPWC 2005.

[14] Zhu Qiankun, XuTingxue, Zhou Hongqing, Yang Chunying, Li Tingjun, "A Mobile Ad Hoc Networks AlgorithmImprovedAODV Protocol", 2011 International Conference on Power Electronics and Engineering Application (PEEA 2011) ELSEVIER Procedia Engineering 23 (2011) 229 - 234.

[15] J. S. Kim, Q.Zhang and D.P.Agarwal, "Probablistic broadcasting based on coverage area and neighbor coverage in mobile ad-hoc networks," in Global Telecommunications Workshop, 2004, Globe Com Workshops 2004. IEEE, pp96-101.

[16] J. D. Abdulai, M. Ould-Khaoua, L. M. Mackenzie, and A. Mohammed, " Neighbour Coverage: A dynamic probabilistic route discovery for mobile adhoc networks," in Performance Evolution of Computer And Telecommunication Systems. 2008. SPECTS 2008. International Symposium on.IEEE, 2008, pp.165-172.

[17] Ali Mohamed E.Ejmaa, ShamalaSubramanium, Zuriati Ahmed Zukarnain, Zurina Mohd Hanapi,'Neighbour based Dynamic Connectivity Factor Routing Protocol for Mobile Adhoc Network", Journal of IEEE Acess,vol.10, October 2016.

[18] Samar, P., Pearlman, M. R. and Haas, Z. J., "Independent zone routing: an adaptive hybrid routing framework for ad hoc wireless networks", IEEE/ACM Transactions on Networking (TON), Vol. 12, pp. 595-608.

[19] Sulaiman,T.H, Al-Raweshidy, H.S,"Centralised Link-State Routing in ZRP”, Personal, Indoor and Mobile Radio Communications, 2006 IEEE 17th International Symposium on , 11-14 Sept. 2006, pp. 1-5.

[20] Tabash, I. K., Ahmad, N. and Beg, S., "Performance Evaluation of TCP Reno and Vegas over different routing protocols for MANETs", IEEE 4th International symposium on Advanced Networks and Telecommunication Systems, IEEE Xplore, pp. 82-84.

[21] Issariyakul, T, and Hossain, E,'Introduction to Network Simulator NS", Springer, US 2009

[22] Salleh, A. U., Ishak, Z., Muhammad, N. and Jamaludin. M. D, "Trace Analyzer for NS-2", IEEE, Student Conference on Research and Development (SCOReD), Malaysia, 2006, pp. 29-32. 